\title{
Ergonomics: Application in Industries
}

\author{
Ravi Gupta, Om Prakash Mahto, Prof Prakash Kumar, Prof Rakesh \\ ( $7^{\text {th }}$ sem. Production Engg.) , BIT SINDRI \\ ( $7^{\text {th }}$ sem. Production Engg.), BIT SINDRI \\ (Asst. Prof. Deppt. of Production Engg.), BIT SINDRI \\ (Asst. Prof. Deppt. of Production Engg.), BIT SINDRI
}

\begin{abstract}
Ergonomics is one of the major point of concern in the manufacturing of any product or commodity in any industries or workshops. It deals with the study of men machine and work environment for achieving optimal performance without causing any physiological and psychological discomfort. This paper presents an overview of the situations in workplaces (industries; workshops etc.) which would assist in user friendlyenvironment and hence will lead to good scale of PRODUCTION.
\end{abstract}

\section{Introduction}

Ergonomics is concerned with making the workplaceas efficient, safe and comfortable as possible.Effective application of ergonomics in work systemdesign can achieve a balance between workercharacteristics and task demands. This can enhance operator productivity provide worker safety andphysical and mental well-being and job satisfaction.Many research studies have shown positive effects design.

Research studies in ergonomics have also produced data and guidelines for industrial applications. Thefeatures of ergonomic design of machines, workstations, and facilities are well known.However, there is still a low level of acceptance andlimited application in industries, especially indeveloping countries. The main concern of worksystem design is usually the improvement ofmachines and tools. Inadequate or no consideration isgiven to the work system design as a whole.Therefore, poorly designed work systems are acommon place in industry. Neglect ofergonomic principles brings inefficiency and pain tothe workforce. An ergonomically deficient workplacecan cause physical and emotional stress, lowproductivity and poor quality of work .Workstation should be laid out such that it minimizesthe working area so that while carrying out theoperations the worker could use shorter motions andexpend less energy and thus reduce fatigue. Similarly there are many more points of concern which assists or helps he workforce for a greater productivity rate which is illustrated in the coming sections.

\section{Basic Approach In Ergonomics}

Ergonomics originated as a consequence of the design and operational problems presented by new work systems that have evolve with the advance of technology .In the context two approaches, viz, "feed the man to the job" or FMJ or feed the job to the man FJM, have been suggested a viable alternative to improve and sustain productivity and economy of human machine work systems with job satisfaction, health and capability of humans as the core issue or objective. It has also become clear that FJM is almost always the superior approach to the design of work system. The underlying assumptions of FJM approach are that a suitable set of operators characteristic can be specified around which a job can be designed, and that this can be done for any job.

\section{Purpose Of Ergonomics}

Identify and remove the work stresses that adverselyaffects health, safety and efficiency of workers.

- To provide safe and productive workplace.

- To achieve better productivity.

- To comply with regulatory bodies.

4. Tools for achieving ergonomics in workshops and industries:-

I. Industrial Scissors Lifts (Lift Tables)Whenever we require movement of the application from bottom to top we require Industrial scissors. These tables can includevariations to facilitate horizontal movement on the deck such as conveyors or ball transfers. The entire unit is movable and directional adjustments can be made due to its portable nature. Upright and angular positioning of loads can be done by adding tilting and adjusting devices;depending upon the source of power mode of use and level of production these scissors have been widely accepted in various industries and plants. Power source can be hydraulic or electric and in small cases it can be manual .It is being used in hydraulic pumps and lifts. 


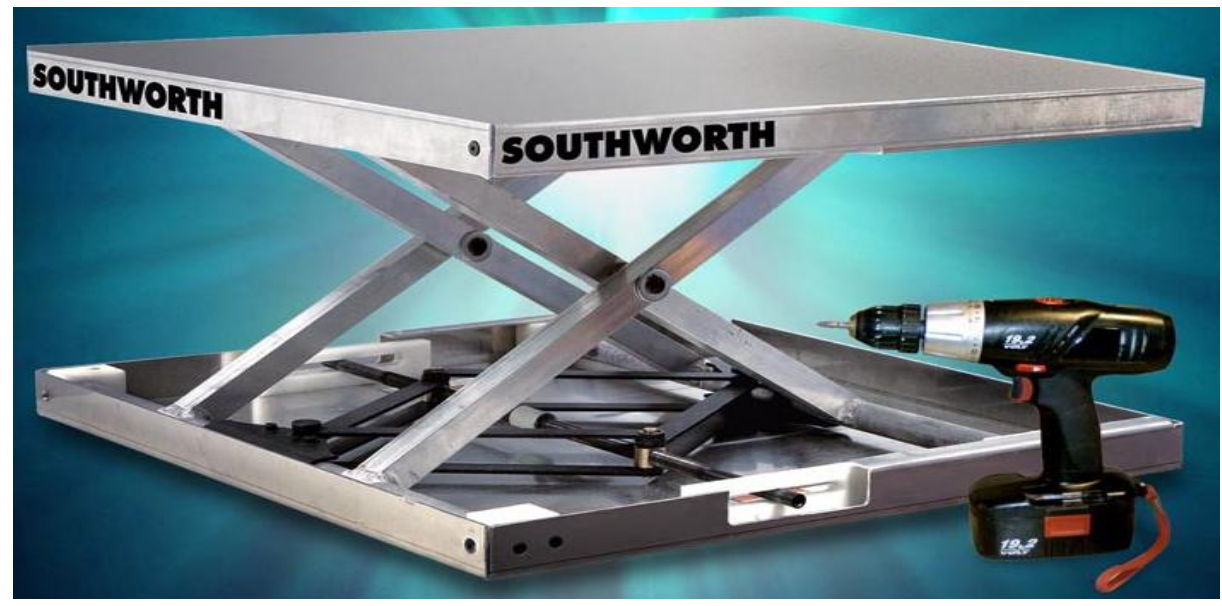

\section{Adjustable Worker Elevation Platform}

AWEP are used in many industries and plants it enables the workers to reach at the job place being at any considerable altitude, hence facilitating the work at any position there are many industries where workers have to work at elevated positions and it becomes quite difficult for them to reach and work at that height by means of any harness or ladder or any considerable equipment of such category hence AWEP is widely accepted.these platforms are not only used in makeshifts but are safer too .In non adjustable platforms it gets very difficult to work for the workers of different heights to work at the same level sometimes it is easier for the short heighted workers and at times it facilitates the longer one and hence affect the favourable ERGONOMIC conditions and hence will led to slower rate of work and impaired productivity. AWEP is more fruitful in longer shifts of work because it will consume a lot of time if the worker goes up and down the platform now and then because the entire system again needs to be readjusted at same level of work position. The size of AWEP varies depending upon the size,capacity,and production rate and type of job that company deals with.

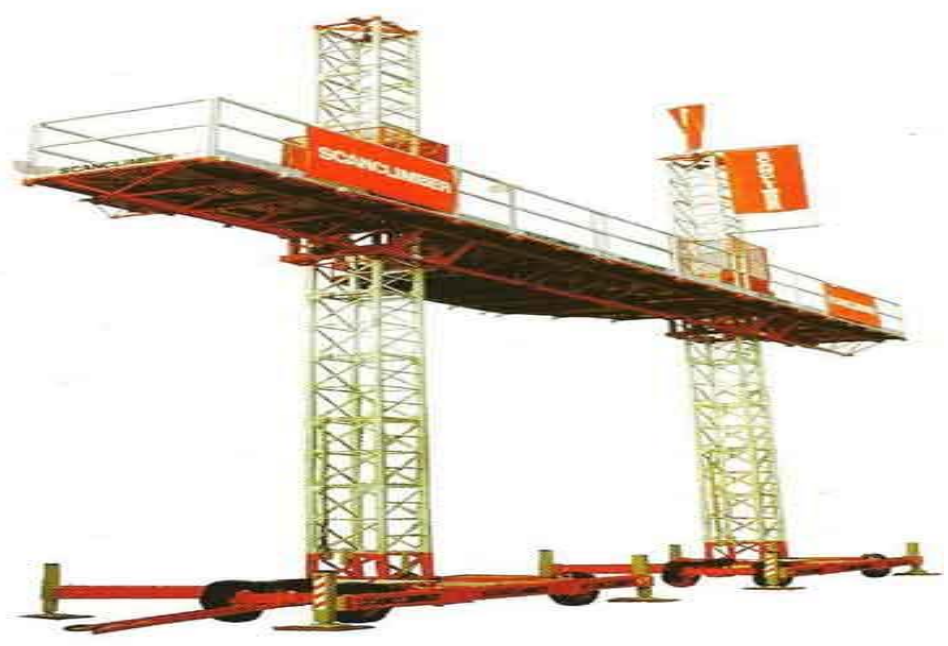

\section{Balancers}

These overhead devices provide and perform functions similar to overhead hoists in that they can lift and lowera load. The balancer configurations and suspensions are similar to a hoist.

The balancer functions differently from a hoist. The functional difference is indicated in the name "balancer."A balancer balances the load in a near weightless condition during the lifting operation. This feature allows the operator to move the load easily. Balancers are often used for awkward and/or rapid load movements.Balancers can also be used to suspend equipment which is used in repetitive operation. A variety of controloptions are available. A very broad range of load handling devices (end effectors) can expand this product's.Balancers are typically supported on small jibs, light monorail systems or tubular track monorailsystems, or as part of a workstation.Both air-powered and electronically driven balancers are commonly available. Balancers can weigh up toapproximately $100 \mathrm{lbs}$. and have approximate lifting capacities 
of

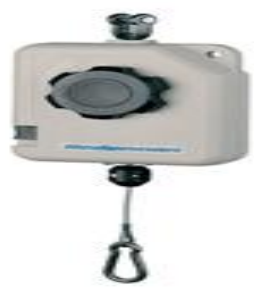

500

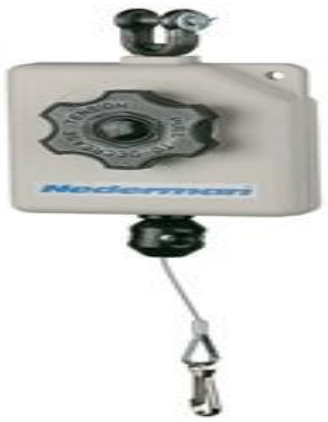

lbs.

\section{Manipulators}

A manipulator has a mechanical arm which can provide sideways and upright movement to the loads. It can be attached or combined with other mechanical devices and equipments and facilitate works which are more significant than the work or action provided by hoists or balancers. It can be attached with power cylinders and mechanical arms etc. Generally actions or work are done at a single commodity at single time.Manipulators can be floor-mounted, column-mounted, mounted overhead on a rail system orattached to a ceiling. The machines are generally operator-controlled at or near the load control device. The operator can pick, lift, move and place the device to the position where it is required or the specific work is going on. The load is in a near weightless condition similar to the balancers. It consumes more time than the balancers but are useful at places where single or very few workforce is available .Manipulators and balancers can be designed for a specific application .Lift and lowered distances are generally fixed in case of manipulators but if we use multiple folded arms in place of long and heavy arms we can overcome this drawback though calculations will be needed that how many numbers of links and nodes are acceptable in lifting a load of particular given weight.

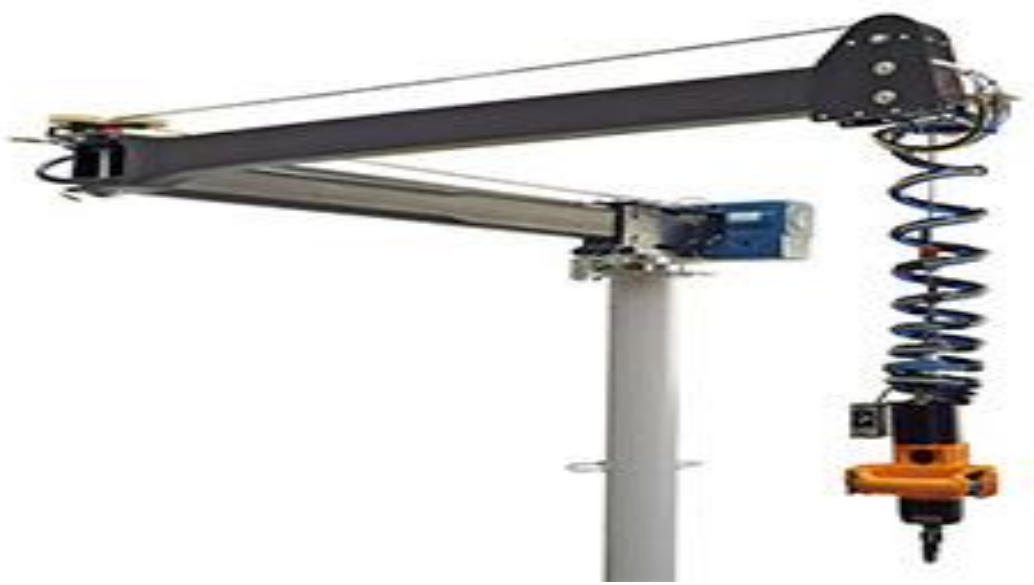

\section{Workstation Cranes}

Enclosed track workstation cranes are ergonomically designed for lighter loads, from 150 lbs. to 4,000 lbs capacities.Powered horizontal push movement can be provided with the help of cranes. The high strength enclosed track of the cranes and its dynamic track design and working mechanism helps to keep the work surfaces clean. The tracks' low weight per footreduces the dead weight, which makes for easier movement, increased worker safety and increased productivity.Enclosed track workstation bridge cranes push very easily typically 1 pound of force for every 100 pounds of load. Thisis much easier than an I-beam crane system that typically takes 3 pounds of force to move every 100 pounds of load.These cranes are ergonomically designed and are moved upon wheels so there is ease in movement and less friction is generated and the cranes have longer life. Exact job positioning can be done and the working conditions are safe;less fatigue; user friendly but a giant and dynamic design construction is required in setting up such cranes. Generally and looking at the economic aspects we can economically these Cranes are widely used in heavy Industries and in almost every Industries facilitated and attached with hoists ,balancers ,ropes, pulleys pick and place mechanism they can be used in lifting and transporting too. Equipment configurations include single or double girder bridge cranes, jib cranes and monorails.Both steel and aluminium cranes are available. Types of cranes are 
Overhead

Jib Crane

Gantry Crane

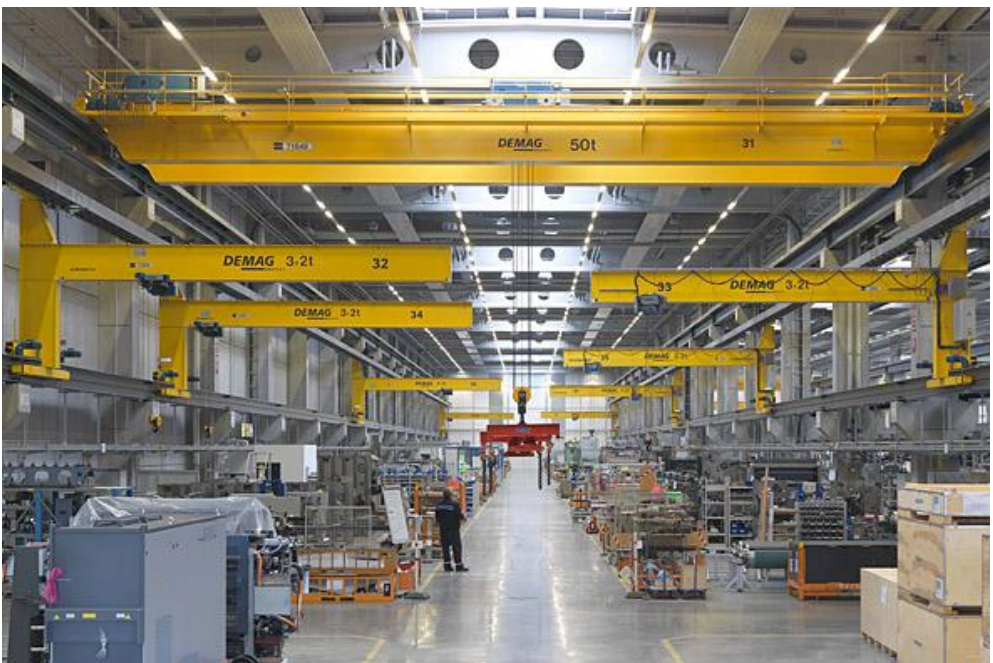

\section{Workstations}

In constructing any workstation or any area of working stress is given on its ergonomic aspects so that that the conditions prevailing over there supports the workforce and hence will yield to better productivity. Loads up to certain weight must being moved and worked by hands and for the load above certain weight lifts and hoists etc must be used depending upon the load and the ease of motion wanted. In any offices tables must be shaped in a semicircular platform so that each and every items and files in the table are easily seen and are within the reach of our hand without standing up or stretching our hands going beyond our comfortable limits. Resting and sitting tables and tools must be arranged beside every machine and at operating points so that the worker may have some rest during the Idle time. Similarly the workshop must be designed in such a way so that the product follows unidirectional flow in the PRODUCT CYCLE when observed in its cycle process and in the string and flow diagrams.

\section{VIII.Conveyors}

Conveyor belts are used in Industries to serve as a faster means of transporting devices and loads from one point of operation to another. Generally it is used in packaging and assembling small amounts of products together. It is very fruitful in those Industries very continuous and repetitive operations are carried out in a small amount of time and there is very little or no tolerance for delays. A conveyor provides an ergonomic advantage to the worker by providing a mechanized means of moving work tothe worker. Expandable conveyors are ideal for assisting workers with tasks such as loading orunloading trucks andtrailers.

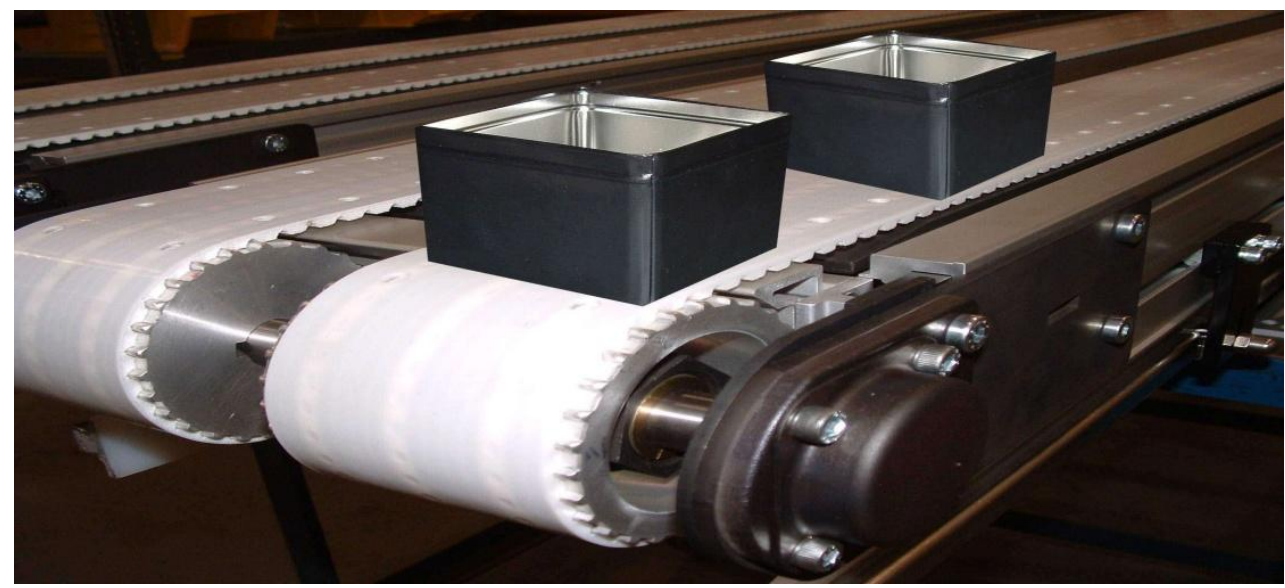

Various types or Industries where we can use conveyors are

Belt conveyors in transferring

Roller conveyors 
Screw conveyor

Monorail

Pipeline conveyor etc.

Conveyors are generally useful when we are working on uniform loads and the products follow the same route while being processed .These are generally system automated for better efficiency and result.

\section{IX.Container Tilters}

Containers, boxes and baskets are widely used to store and transport parts and products. Although they are efficient, loading and unloading them requires motions that can be unsafe for workers. Regardless ofhow light the storedparts are, workers must repetitively bend, stoop, reach and lift as they work their way to the bottom of these containers. To make the process safer and more productive, the container should be moved up and toward the worker as it isunloaded. Proper positioning can eliminate the need for bending, stretching, reaching and unnecessary lifting.Pictured are portable tilters which allow containers to be picked up, moved into position, and tilted for easy access. There are similar stationary models which allow containers to be directly placed on the tilter by hand pallet trucks orfork trucks. In addition, there are floor height pivot point devices and tilters that mount on lift tables and other bases.There are nearly as many tilter designs as there are container styles, and application information must be carefullyconsidered before equipment selection. Special attention should be given to all container dimensions and the weightand configuration of the part.

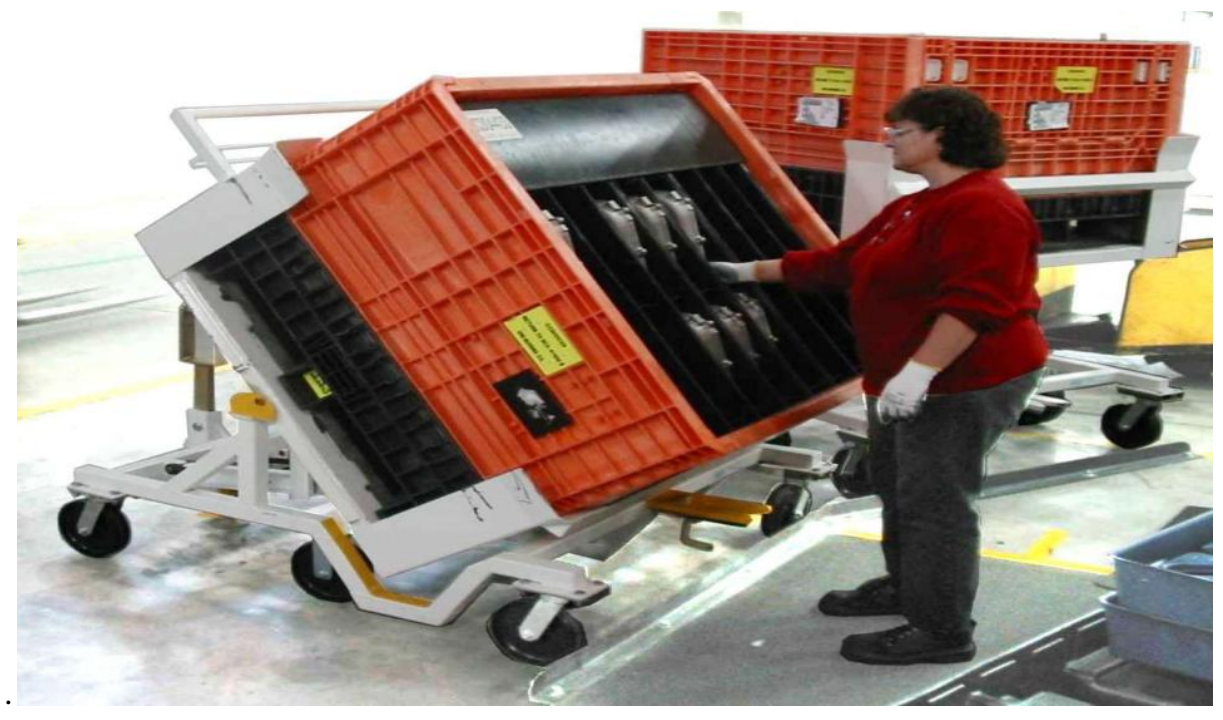

\section{Ergonomics In India}

The Indian Society Of Ergonomics was established in 1983 and is the only professional body representing human factor professionals in India.It is affiliated to the international ergonomics association (IEA) and nominates members to its committees. So far,eight international conference have been organised by the Indian society of ergonomics with full proceedings published. The society publishes a quarterly newsletter. Members of the Indian society of ergonomics belong to a wide variety of fields, including physiology, psychology, home science, industrial design, product design.,occupational health, industrial safety and engineering,reflecting the multi disciplinary nature of the subject.

\section{Application}

Processing and canning industries like tinplate, fritolay uses fast moving processing units and conveyor belts for fast packaging processes.

Sugar and pulp industries uses machine driven computer automated devices for fast processind rate.

Modern offices in INDIA or anywhere in world which are be newly constructed are giving stress on ergonomics aspect of the workforce and the working staff.A newly constructed office of TCS in jsr is a perfect example of this setup.

Similar ergonomics aspect of the industries and offices are maintained various places for manufacturing processing and packaging process where less stress is given on the workforce. 


\section{Drawbacks In India And Other Developing Countries}

In INDIA and in other developing countries there is a mad race of production and very less or no concern is taken about the ergonomic aspects of the workforce. In industries and in workshops or in other working area ergonomic tools are not very frequently seen this is because of lack of technological development and cheap labour is also available as the literacy rate is very less in developing countries,Lack of skill labour and lack of technology is also one of the primary factors.

The major factors why ergonomic condition is lacking in developing countries are:

1. Literacy rate is very low so cheap labour is easily available.

2. No implementation of the laws and acts framed by government bodies.like Indian Factory Act gives stress on the conditions which will lead to a good ergonomically flourishing condition in industries and workplace,but there is more or less no implementation of these norms.

3. Technology is more or less dependent on other developed countries,for eg. HEC. a Indo-Soviet collaboration set up is more or less dependent on Russia for its technical development use of conveyor belts and other ergonomic tools is still lacking over there and consequently it has lead to low production rate.

4. Small scale industries uses human labour at a mad race for matching up with market completion as they are unaware of the potential of ergonomics.

\section{Conclusion}

Now, we have marched towards the end of our case study . Detail study of it reveal that in developing countries more or less no concern is given on ergonomics aspects over the industrial development. various ergonomics tools have been detailed in this case study which let to the overall development of the workforce and hence will result good production rate without providing any discomfort at the manufacturing level.

\section{Reference}

[1]. Wikipedia:Human factors and Ergonomics.

[2]. Industrial Engineering And Management by Dr.B.Kumar

[3]. The publication Work Practices Guide forManual Lifting is available from NIOSH.

[4]. Industrial Engineering and Production Management by Martend Telsang

[5]. EASE relevant datas and the contents were collected from it very useful help was derived and some of the content were unchanged.

[6]. 6.google.com and its various links for images. 